\title{
Use of Magnesium in Traumatic Brain Injury
}

\author{
Ananda P. Sen* and Anil Gulati ${ }^{\dagger}$ \\ *EndogenX, Los Gatos, California 95032; and ${ }^{\dagger}$ Midwestern University, Chicago College of Pharmacy, Downers Grove, \\ Illinois 60515
}

\begin{abstract}
Summary: Depletion of magnesium is observed in animal brain and in human blood after brain injury. Treatment with magnesium attenuates the pathological and behavioral changes in rats with brain injury; however, the therapeutic effect of magnesium has not been consistently observed in humans with traumatic brain injury (TBI). Secondary brain insults are observed in patients with brain injury, which adversely affect clinical outcome. Systemic administration studies in rats have shown that magnesium enters the brain; however, inducing hypermagnesemia in humans did not concomitantly increase magnesium levels in the CSF. We hypothesize that the neuroprotective effects of magnesium in TBI patients could be observed by increasing its brain bioavailability with mannitol. Here, we review the role of magnesium in brain injury, preclinical studies in brain injury, clinical safety and efficacy studies in TBI patients, brain bioavailability studies in rat, and
\end{abstract}

pharmacokinetic studies in humans with brain injury. Neurodegeneration after brain injury involves multiple biochemical pathways. Treatment with a single agent has often resulted in poor efficacy at a safe dose or toxicity at a therapeutic dose. A successful neuroprotective therapy needs to be aimed at homeostatic control of these pathways with multiple agents. Other pharmacological agents, such as dexanabinol and progesterone, and physiological interventions, with hypothermia and hyperoxia, have been studied for the treatment of brain injury. Treatment with magnesium and hypothermia has shown favorable outcome in rats with cerebral ischemia. We conclude that coadministration of magnesium and mannitol with pharmacological and physiological agents could be an effective neuroprotective regimen for the treatment of TBI. Key Words: Traumatic brain injury, magnesium, neuroprotection, hyperoxia, hypothermia.

\section{INTRODUCTION}

Traumatic brain injury (TBI) occurs when a sudden trauma causes damage to the brain. TBI affects people of all ages and manifests itself with high morbidity and mortality. The events following TBI in morbid patients result in permanent disability with lifelong financial, medical, emotional, family, and social consequences.

A depletion of magnesium has been observed in brain of animals and in blood of humans after brain injury. Administration of magnesium attenuated the neurobehavioral and pathological changes in animal models of brain injury. In TBI patients, however, two prospective clinical studies with magnesium as a neuroprotective agent showed conflicting results. ${ }^{1,2}$ Secondary brain insults and other parameters have been observed to adversely affect the clinical outcome in patients with brain injuries, and these could have unfavorably affected the results of the clinical studies on therapeutic efficacy of

Address correspondence and reprint requests to: Dr. Ananda P. Sen, $\mathrm{PhD}$, EndogenX, 15595 Los Gatos Boulevard, Las Gatos, CA 95032. E-mail: asen@endogenx.com. magnesium in TBI patients. Pharmacokinetic and pharmacodynamic studies in normal rats have shown that after systemic administration magnesium was able to enter the brain, ${ }^{3,4}$ but pharmacokinetic studies in humans with brain insults have shown that parenteral administration of magnesium did not cause a concomitant rise of magnesium in the CSF. ${ }^{5-7}$ Regulation of brain and CSF by the central nervous system may limit the blood-brain barrier (BBB) permeability for peripherally administered magnesium, which could be a limiting factor in its efficacy in TBI patients.

Multiple biochemical pathways are involved in the brain degeneration process that follows TBI. Treatment with a single agent may result in lack of efficacy at a safe dose or adverse effects at a therapeutic dose or upon repeated administration. A clinically successful neuroprotective therapy must be aimed at controlling these pathways with multiple agents, for a synergetic affect. Besides magnesium, several pharmacological agents ${ }^{8,9}$ and physiological interventions, such as hyperoxia and hypothermia (reviewed elsewhere in this issue), are being studied for the treatment of TBI. Among the phar- 
macological agents, dexanabinol and progesterone have been studied in clinical trials. Dexanabinol was safe but not efficacious in a phase III study. ${ }^{10}$ Progesterone is currently in a phase III clinical study (http://www.Clinicaltrials.gov Identifier: NCT00822900). We hypothesize that increasing brain bioavailability of magnesium with mannitol, along with cotherapy with pharmacological agents and physiological interventions at their safe and lowest-effective doses could lead to a clinically effective neuroprotective regimen for the treatment of TBI.

\section{PATHOPHYSIOLOGY OF TRAUMATIC BRAIN INJURY}

The pathophysiology of TBI occurs in two phases, a primary phase and a secondary phase. During the primary phase, there is localized neuronal death at the site of impact as a direct consequence of the biomechanical injury. During this phase, there is a decrease in cerebral blood flow, resulting in hypoxia and ischemia with an increase of brain oxidative metabolism. ${ }^{11,12}$ A shortage of glucose and an acute increase in energy demand results in anaerobic metabolism of glucose (hyperglycolysis) and release of lactate. These exacerbate the effects of the primary physical insult. An accumulation of lactate and decrease in glucose concentration have been observed in TBI patients. ${ }^{13,14}$ An increase in lactate to pyruvate $(\mathrm{L} / \mathrm{P})$ ratio is a sensitive indicator of brain ischemia, and increases in $\mathrm{L} / \mathrm{P}$ ratio have been observed after subarachnoid hemorrhage. ${ }^{15,16}$ Brain edema of cellular nature is frequently observed, which results in an increase of intracranial pressure (ICP) for more than 5 days. ${ }^{17}$ Increased ICP causes structural damage and herniation and reduces cerebral perfusion pressure and cerebral blood flow, leading to further exacerbation of ischemia. In TBI patients, ICP $>20 \mathrm{mmHg}$ has been shown to contribute to neurological deterioration and mortality. $^{18}$

The primary phase activates the subsequent and irreversible secondary phase, with long-term effects. During this secondary phase, several imbalances in the biochemical homeostatic pathways and factors contribute to the cascade of events resulting in irreversible neuronal degeneration and death, distal to the injured site. Excitotoxicity with excessive release of glutamate ${ }^{19}$ occurs and causes an overstimulation of the postsynaptic NMDA receptors that control the ionic channels. (Some glutamate is also released as a result of hypoxia, in the primary phase.) There is a failure of calcium homeostasis and a massive influx of sodium, calcium, and water, with delayed calcium deregulation. Ischemia due to increased ICP in the primary phase also adversely affects the secondary phase. Generation of oxygen free radicals and mitochondrial dysfunctions lead to calcium accumulation, depletion of ATP, generation of reactive oxygen species, and apoptosis. ${ }^{20,21}$ Together, these events result in neurodegeneration.

\section{MECHANISMS OF NEUROPROTECTIVE ACTION OF MAGNESIUM}

Magnesium has an important role in homeostatic regulation of the pathways involved in the delayed secondary phase of brain injury. ${ }^{22}$ During normal physiological processes, magnesium is a noncompetitive inhibitor of the NMDA receptors ${ }^{23}$ and it thereby regulates calcium influx. ${ }^{24}$ In the cascade of events following TBI, there is a depletion of magnesium and its homeostatic control of the NMDA receptors is lost. This leads to a massive influx of calcium, resulting in neuronal degeneration and cell death. ${ }^{22}$

Magnesium deficiency was associated with increased oxidative stress in rats through a reduction in plasma antioxidants and increased lipid peroxidation, possibly due to increased susceptibility of body organs to free radical injury. ${ }^{25}$ Administration of magnesium to dogs during coronary occlusion attenuated the increase of free radicals during reperfusion. ${ }^{26}$ These findings were confirmed in TBI patients: administration of magnesium sulfate reduced oxidative stress after TBI in humans. ${ }^{27}$

In patients with subarachnoid hemorrhage undergoing temporary cerebral artery occlusion for clipping of cerebral aneurysm, treatment with magnesium sulfate dilated the leptomeningeal arteries and enhanced collateral blood flow and tissue oxygenation. ${ }^{28}$

Molecular mechanisms have been studied on the efficacy of magnesium in attenuating the neurological damage in TBI. The tumor-suppressor gene TP53 (alias p53) encodes the cellular tumor antigen p53 and is a regulator of neuronal apoptosis. Upregulation of TP53 mRNA was observed in the cortex, thalamus, and hippocampus after brain injury in rats. ${ }^{29}$ Treatment with magnesium reduced the upregulation of the TP53 gene and apoptosis in rats with brain injury. ${ }^{30}$

Water homeostasis is critical for optimal neuronal function, and any alteration of intracellular and extracellular water content will disrupt ionic homeostasis and electrical conduction. ${ }^{31}$ Aquaporin-4, a membrane protein found in brain astrocytes of mammals, has an important role in the homeostasis of water. It is upregulated in brain injury, and thus leads to an increase in brain water content resulting in brain edema. In rats with brain injury, magnesium downregulated aquaporin-4 channels ${ }^{32}$ and thereby attenuated brain edema. ${ }^{33}$

\section{PRECLINICAL STUDIES WITH MAGNESIUM IN BRAIN INJURY}

A disruption of magnesium homeostasis has been observed after brain injury, and normalizing magnesium 
levels has resulted in improved neurological recoveries. A decline in ionized magnesium concentrations in rat brain was observed after brain injury that correlated with neurological outcome and behavioral deficits in rats. ${ }^{34} \mathrm{~A}$ significant positive and linear correlation was established between ionized magnesium levels measured at $24 \mathrm{~h}$ after injury and motor outcome at 1 and 2 weeks. ${ }^{35}$

Several studies in rats have shown that treatment with magnesium after brain injury had neuroprotective effects on motor and behavioral outcome $e^{22,36-38}$ in a dose-dependent manner. ${ }^{39,40}$ Cortical damage was attenuated after treatment with magnesium in rats. ${ }^{41}$ Magnesium administered at $24 \mathrm{~h}$ improved motor outcome and behavioral parameters in rats with brain injury. ${ }^{42,43}$ Magnesium reversed persistent motor and cognitive deficits with reduction of post-traumatic stress and anxiety after brain injury in rats. ${ }^{44}$

Magnesium therapy after TBI may not always improve the mortality and morbidity of the subjects. In patients with severe TBI, a subdural hematoma is often present, which has developed subsequent to the primary injury. In a rat model of impact acceleration, diffuse brain trauma frequently caused extensive subdural hematoma. ${ }^{45}$ In rats diagnosed with subdural hematoma from postmortem examination, previous postinjury administration of magnesium did not show improvement in motor activity. In rats with no subdural hematoma, administration of magnesium did show significant improvement in motor activity. The free magnesium concentration in brains of the magnesium-treated, hematoma group demonstrated a biphasic decline. There was an initial and immediate decline, recovery of brain magnesium levels subsequent to magnesium treatment, and then a subsequent decline again. The subsequent decline in brain magnesium concentration was not observed in the magnesium-treated, no hematoma group of rats. Development of subdural hematoma after brain injury resulted in a decline of brain magnesium concentration, even after magnesium treatment. $^{45}$

\section{MAGNESIUM IN HUMANS WITH TRAUMATIC BRAIN INJURY}

Disruption of magnesium homeostasis has been observed in the pathophysiological events after TBI in humans. In TBI patients, a graded deficit of serum ionized magnesium concentration has been observed ${ }^{46}$ that represents an early indicator of ultimate, irreversible brain damage. An early measurement of ionized magnesium could be a clinically useful predictor of the late outcome after head injury. ${ }^{47}$ Increased urinary loss of magnesium after TBI in humans appears to be one of the factors contributing to its depletion. ${ }^{48}$

Ionized magnesium is the physiologically active form that can enter the brain. Its levels are affected by the total magnesium concentration in the CSF, and CSF magne- sium concentration is used as a surrogate marker of brain magnesium concentration. ${ }^{6}$ In a comparative analysis of serum and CSF magnesium concentrations in TBI patients with a mean Glasgow Coma Scale (GCS) score of 8.7, serum ionized magnesium concentration correlated with the GCS scores. ${ }^{49}$ In another study, elevated magnesium levels were observed in the ventricular CSF of TBI patients with a mean GCS score of 5.6. ${ }^{50}$ In humans with graded TBI with GCS scores of 4-6 (extensive, penetrating injury) and 13-15 (mild, closed injury), a time-dependent increase of plasma ionized magnesium was observed for 7 days. ${ }^{27}$ There was a persistent production of reactive oxygen species malondialdehyde and a delayed decrease of the antioxidant superoxide dismutase, suggesting increased antioxidant utilization. The study showed a correlation between the decline in plasma ionized magnesium concentration and the development of oxidative stress in TBI. ${ }^{27}$

\section{CLINICAL STUDIES WITH MAGNESIUM IN TRAUMATIC BRAIN INJURY}

\section{Safety and tolerability studies with magnesium}

In the Turin Lidomag Pilot Study, a high dose of magnesium with a low dose of lidocaine was administered for 3 days to 32 patients with severe TBI and a GCS score of 3-8. ${ }^{51}$ Magnesium was administered intravenously at an initiation dose of $70 \mathrm{mg} / \mathrm{kg}$, followed by a maintenance dose of $15 \mathrm{mg} / \mathrm{kg}$ per hour. Lidocaine was administered intravenously at an initiation dose of 1.5 $\mathrm{mg} / \mathrm{kg}$, followed by a maintenance dose of $1 \mathrm{mg} / \mathrm{kg}$ per hour. The patients were monitored for 6 months. The study showed that a combination of magnesium and lidocaine was safe and well tolerated, with lesser mortality.

The safety of magnesium was studied in pediatric patients suffering from TBI. ${ }^{52}$ Six patients with ages ranging from 3.4 to 15.4 years and GCS scores of 3-11 were recruited, four of whom were placed on magnesium dosing within $17-56 \mathrm{~h}$ of injury; the other two patients served as controls and were administered normal saline. Magnesium was administered intravenously at an initiation dose of $50 \mathrm{mg} / \mathrm{kg}$ and a maximal dose of $4 \mathrm{~g}$, administered over $30 \mathrm{~min}$; this was followed by a maintenance dose of $8.3 \mathrm{mg} / \mathrm{kg}$ per hour, administered intravenously, for $24 \mathrm{~h}$. A follow-up examination with neuropsychological testing and cranial MRI at 3 months after the injury showed no adverse hemodynamic effects.

\section{Efficacy studies with magnesium}

In contrast to the preclinical studies, clinical studies with magnesium treatment after TBI have failed to show consistent beneficial effects. In particular, two prospective clinical studies have reported differing effects of magnesium in TBI patients. ${ }^{1,2}$ 
In a double-blind clinical trial reported by Temkin et al., ${ }^{1}$ the effects of two doses of magnesium sulfate were studied in 499 patients with moderate to severe TBI. Magnesium was administered intravenously within $8 \mathrm{~h}$ of injury at a loading dose, followed by a continuous infusion for 5 days. The higher dose was targeted to achieve serum levels of $1.25-2.5 \mathrm{mmol} / \mathrm{L}$. A high mortality was observed at 6 months, and the magnesium dose was lowered to achieve serum levels of $1.0-1.85 \mathrm{mmol} / \mathrm{L}$. No beneficial effects were observed with a composite primary outcome measure based on mortality, seizures, measures of functional status, and neuropsychological tests conducted at 6 months.

In this clinical trial, the patients upon admission had a 1) GCS score of 3-12, or 2) needed intracranial surgery within $8 \mathrm{~h}$ of injury, or 3) if intubated, had a GCS motor score of 1-5 without pharmacological paralysis. ${ }^{1}$ A better composite outcome was observed at 6 months with both the low and high doses of magnesium in patients with moderate severity of injury. No data were reported to correlate the severity of injury with the dose of magnesium or placebo and mortality. Had this been done, the results might have been interpreted differently.

A correlation between age and morbidity has been observed in TBI patients. In a study on the effects of age on outcome in 235 TBI patients, lower Functional Independence Measure (FIM) scores were observed at 6 months in patients above 65 years of age, compared with younger patients. ${ }^{53}$ In the clinical trial reported by Temkin et al. ${ }^{1}$ on magnesium in TBI, the exclusion criteria excluded patients less than 14 years of age; no upper limit of age was reported, and the mean age for all the patients was 34.3 years (SD, 16.6) for both the high-dose and low-dose magnesium groups and 34.4 years (SD, 17.8) for the placebo group. The patients were stratified into two groups, with ages below and above 40 years. In the placebo groups, better composite outcome was observed in patients below 40 years than the patients above 40 years. In the patients below 40 years, however, no difference on composite outcome was observed between either the low or high doses of magnesium and placebo treatments. In patients above 40 years, the group with a high dose of magnesium showed better outcome than the placebo group, but the low-dose group did not show any difference from the placebo group. Any correlations among severity of injury, age, treatment, and outcome were not reported.

A correlation between age, morbidity at discharge, and outcome was reported in yet another prospective multicenter trial. ${ }^{54}$ In that study of 236 patients, the TBI patients above 60 years who were discharged with a Glasgow Outcome Score (GOS) of less than 4 showed lower FIM Scores at 1 year, compared with younger patients. In the clinical trial reported by Temkin et al., ${ }^{1}$ no data on GOS (or any other scoring system) upon discharge were reported. Inclusion of data on severity of injury, age, and outcomes at discharge and at 6 months might have allowed different interpretation of the results.

Hypotension and hypoxia, frequently observed after TBI, contribute to increased morbidity and mortality. A prospective study of 717 TBI patients has shown $50 \%$ mortality in those with systolic blood pressure (SBP) less than $90 \mathrm{mmHg}$ and $57 \%$ mortality in patients with both hypotension and hypoxia with a $\mathrm{PaO}_{2}$ less than 60 $\mathrm{mmHg}$, compared with $27 \%$ mortality in patients without any hypotension and hypoxia. ${ }^{55}$ A mortality of $83 \%$ was observed in TBI patients with a SBP below $90 \mathrm{mmHg}$ within $24 \mathrm{~h}$ of admission, compared with $45 \%$ in patients with SBP above $90 \mathrm{mmHg} .{ }^{56}$ In a study of 107 patients, a linear correlation was observed between the number of hypotensive episodes with SBP below $90 \mathrm{mmHg}$ and mortality during initial resuscitation. ${ }^{57}$ Patients with one hypotensive episode had a $53 \%$ mortality rate, whereas $100 \%$ mortality was observed in patients with three or more hypotensive episodes. No effect of hypoxia on mortality was observed.

In the clinical trial reported by Temkin et al. ${ }^{1}$ on magnesium in TBI patients, the predosing mean SBP for the combined group patients treated with low or high doses of magnesium was $128 \mathrm{mmHg}(\mathrm{SD}, 23)$ and 129 $\mathrm{mmHg}(\mathrm{SD}, 20)$ for the placebo group. The diastolic blood pressure for the combined patients was $77 \mathrm{mmHg}$ (SD, 17) for the magnesium group and $77 \mathrm{mmHg}$ (SD, 15) for the placebo group. The blood pressure at admission was not reported. During treatment with both low and high doses of magnesium and placebo, hypotensive episodes with SBP below $90 \mathrm{mmHg}$ was reported in $26-36 \%$ of the patients. Correlation of hypotensive episodes with mortality or composite outcome was not reported. ${ }^{1}$

Physiological response to head injury leads to increased release of cortisol, glucagon, and epinephrine, resulting in gluconeogenesis and stress hyperglycemia. In a prospective study of 267 patients with differing severity of head injuries, patients with severe head injury had more hyperglycemia, with glucose levels above 200 $\mathrm{mg} / \mathrm{dL}$, than patients with moderate injury. ${ }^{58}$ The patients with glucose levels above $200 \mathrm{mg} / \mathrm{dL}$ also showed increased ICP and unfavorable outcome. In a retrospective review of 516 patients, hyperglycemia with glucose levels above $200 \mathrm{mg} / \mathrm{dL}$ in the first $24 \mathrm{~h}$ after brain injury and on days 1-2 after admission was associated with significantly greater infection and mortality. ${ }^{59}$ In 338 patients with severe TBI, the mean arterial pressure and blood glucose levels linearly correlated with mortality, with a stronger relationship between hyperglycemia and increased mortality. ${ }^{60}$ In a prospective study of 896 critically ill trauma patients, early glycemic control resulted in reduced infection and mortality. ${ }^{61}$ In the clinical trial reported by Temkin et al. ${ }^{1}$ on magnesium in TBI pa- 
tients, blood glucose levels were not reported, and it remains unknown whether blood glucose levels adversely affected morbidity and mortality in these patients.

Excessive magnesium is known to cause or exacerbate renal failure. The patients in the clinical trial reported by Temkin et al. ${ }^{1}$ were not screened for renal function, and their urine output was not reported. The time from treatment to death was not reported. Non-neurological organ dysfunction is commonly observed in TBI patients and contributes independently to a worse clinical outcome. ${ }^{62}$

It is not clear whether patients in the Temkin et al. ${ }^{1}$ trial died from the effects of magnesium or from natural progress of brain injury. It was also not reported whether the patients had any preexisting health conditions, and whether they were on other medications or whether the consumed alcohol, tobacco, or had a history of substance abuse.

In another prospective clinical study, reported by Dhandapani et al., ${ }^{2}$ magnesium sulfate was administered within $12 \mathrm{~h}$ of injury to 30 patients with severe closed TBI at initiation doses of $4 \mathrm{~g}$, administered intravenously, over 5-10 minutes and $10 \mathrm{~g}$, administered intramuscularly, followed by a maintenance dose of $5 \mathrm{~g}$ administered intramuscularly every $4 \mathrm{~h}$ for $24 \mathrm{~h}$. The inclusion criteria included patients with closed-head TBI, admission GCS score of 5-8, and age 18-60 years. The exclusion criteria included patients with hypotension with a SBP below $90 \mathrm{mmHg}$ for more than 10 minutes, renal failure, and significant multisystem injury. At the end of 3 months, mortality was $13 \%$ for the patients treated with magnesium and $47 \%$ for the patients treated with placebo. Among the surviving patients, good recovery at 3 months was observed in 54\% of the patients treated with magnesium and in $38 \%$ of the patients on placebo. The patient outcome was evaluated using the 5-point GOS, which may produce false positives. The 8-point GOS-Extended (GOS-E) has been developed to improve on the 5-point GOS. It was not reported whether the study was blinded. The patients were evaluated for only 3 months, whereas the standard evaluation period in most brain injury studies is at least 6 months. The admission blood pressure and blood glucose levels were not reported.

\section{Secondary insults in traumatic brain injury}

Secondary insults have been observed after TBI that adversely affect the clinical outcome and mortality. Hypotension has been related with increased mortality, and hypoxia, hypocapnia, increased ICP, and acidosis were associated with poor outcome. ${ }^{63}$ From the two prospective clinical trials of magnesium in TBI reported by Temkin et al. ${ }^{1}$ and Dhandapani et al., ${ }^{2}$ it is evident that in clinical trials on brain injuries a study design with more stringent inclusion-exclusion criteria need to be consid- ered, to account for secondary brain insults and parameters likely to adversely affect outcome, such as severity of head injury, multiorgan injury, age limits, renal function, pre-existing health conditions, concomitant medication, use of tobacco and alcohol, and history of substance abuse.

\section{BRAIN BIOAVAILABILITY OF SYSTEMICALLY ADMINISTERED MAGNESIUM}

\section{Preclinical studies}

Pharmacokinetic studies in rats have shown that after intraperitoneal administration of magnesium sulfate, increased levels of magnesium were observed in the cortex and hippocampus. ${ }^{3}$ In a recent pharmacodynamic study, daily intraperitoneal administration of magnesium chloride in rats prior to the acquisition of learning a reference memory task in the Morris water maze produced significant amnesia after 3 days. ${ }^{4}$ Both of these studies proved that after systemic administration, magnesium was able to enter the brain in rats with intact BBB.

\section{Clinical studies}

A marginal increase of magnesium in the CSF was observed after administration of magnesium sulfate intravenously in women with preeclampsia $(n=10){ }^{7}$

In another study of 20 patients undergoing craniotomy, magnesium sulfate administered intravenously at 60 $\mathrm{mg} / \mathrm{kg}$ over 15 minutes produced a maximal plasma magnesium concentration at 30 minutes, with subsequent decreases. However, a significant increase of magnesium in the CSF after 90 minutes, which persisted for more than 4 hours, was observed. A correlation between plasma and CSF magnesium concentrations was not observed. Of the 20 patients, 15 were also administered 0.5 $\mathrm{mL} / \mathrm{kg}$ of mannitol intravenously for better operating conditions. ${ }^{5}$ This dose and route of mannitol should not cause BBB disruption.

In another clinical study, 30 patients with acute brain injury secondary to subarachnoid hemorrhage, TBI, primary intracerebral hemorrhage, subdural hematoma, brain tumor, brain infection, or ischemic stroke were administered an intravenous bolus dose of magnesium sulfate at $20 \mathrm{mmol}(5 \mathrm{~g})$ over 30 minutes. The treatment was given on an average of 5 days after the injury (range, 1-16 days) and was followed by an infusion of magnesium sulfate at $8 \mathrm{mmol} / \mathrm{h}(2 \mathrm{~g} / \mathrm{h})$, which was adjusted to achieve a serum total magnesium range of 2.1-2.5 $\mathrm{mmol} / \mathrm{L}$. The magnesium infusion was terminated at $24 \mathrm{~h}$ from the beginning of bolus dose. Although the serum total magnesium increased by $169 \%$ and the ionized magnesium increased by $132 \%$ from baseline at $12 \mathrm{~h}$, the CSF total magnesium increased by $15 \%$ and the CSF ionized magnesium increased by $11 \%{ }^{6}$ 
Key tenets for a neuroprotective agent include 1) entry into the brain, 2) presence in the brain at a concentration known to be neuroprotective, and 3) presence of an adequate concentration in the brain for a period of time that will improve neuronal survival. ${ }^{6}$ It is evident that after systemic administration in rats with intact BBB, magnesium entered the brain and induced behavioral changes. In humans, however, inducing hypermagnesemia resulted in marginal increase of CSF total and ionized magnesium concentration. Also, the relationship between blood and CSF magnesium concentrations changed with time. From pharmacokinetic studies in humans, it can be concluded that blood magnesium concentration cannot be used to predict the CSF magnesium concentration.

\section{COMBINATION OF MAGNESIUM WITH PHARMACOLOGICAL AGENTS FOR THE TREATMENT OF TRAUMATIC BRAIN INJURY}

Neuronal degeneration during the secondary phase of brain injury after TBI is mediated through multiple biochemical pathways. For clinical success, a neuroprotective therapy must address the homeostatic control of these pathways with a combination of pharmacological agents.

\section{Preclinical studies}

Coadministration of magnesium with pharmacological and nutritional agents has been studied successfully in preclinical models of brain insult. A combination therapy with magnesium and the antioxidant tirilazad significantly improved neurological function and reduced infarct volume in rats with cerebral ischemia. ${ }^{64} \mathrm{~A}$ combination of magnesium with vitamin $\mathrm{B}_{2}$ (riboflavin) significantly improved functional recovery in rats subjected to cortical contusion injury. $^{65}$

\section{Clinical studies}

Pharmacological agents evaluated preclinically for the treatment of brain injury include statins, progesterone, erythropoietin, minocycline, Toll-like receptor agonists, dexanabinol, thyrotropin releasing hormone analogs, and cyclosporin A. ${ }^{8,9}$ Of these, dexanabinol and progesterone have been studied clinically for the treatment of TBI.

A synthetic analog of tetrahydrocannabinol, dexanabinol, has neuroprotectant properties as an NMDA receptor antagonist, free radical scavenger, antioxidant, and inhibitor of tumor necrosis factor- $\alpha{ }^{66-68} \mathrm{~A}$ phase II clinical study of 67 patients, 6-month post-injury follow-up, concluded that dexanabinol was safe and well tolerated in patients with severe TBI with significant control of ICP and cerebral perfusion pressure, and without lowering of SBP to less than $90 \mathrm{mmHg} .{ }^{69}$ However, a phase III randomized placebo-controlled clinical study of dex- anabinol in 861 TBI patients reported it to be safe but not efficacious. ${ }^{10}$

Sex alters the incidence and recovery from TBI, with men experiencing more injury than women. The female steroidal hormone progesterone has been studied as a neuroprotectant in animal models of brain injury. In an in vitro model of spinal cord injury, progesterone protected against glutamate-mediated toxicity. ${ }^{70}$ Progesterone was effective against oxidative stress in in vitro studies. ${ }^{71}$ Progesterone attenuated brain edema ${ }^{72}$ and reduced inflammation ${ }^{73}$ in rats with brain injury. In male and ovariectomized female rats with brain injury, treatment with progesterone improved their motor and cognitive performance with attenuation of caspase- 3 immunoreactivity and reduction of axonal injury. ${ }^{74}$

In the phase II ProTECT clinical study in 100 patients with acute TBI, treatment with progesterone was safe and a 30-day post-injury follow-up showed lower mortality. Also, moderate to good clinical outcome with improved GOS-E scores were observed in patients with moderate TBI (initial GCS 9-12), but no differences were observed between progesterone treatment and placebo groups for patients with severe TBI. ${ }^{75}$ In another clinical study in 159 patients with acute severe TBI (initial GCS $<8$ ), treatment with progesterone significantly improved neurological outcome at 6 months. ${ }^{76} \mathrm{~A}$ phase III clinical study with progesterone in TBI patients is under way (http://www.Clinicaltrials.gov Identifier: NCT00822900).

\section{COMBINATION OF MAGNESIUM WITH PHYSIOLOGICAL INTERVENTIONS FOR THE TREATMENT FOR TRAUMATIC BRAIN INJURY}

\section{Preclinical studies with magnesium and hypothermia}

A combination therapy with magnesium and hypothermia reduced neuronal death ${ }^{77}$ and infarct volume ${ }^{78}$ in rats with cerebral ischemia. A synergistic reduction in infarct volume was observed with the combination of magnesium, tirilazad, and hypothermia in rats with cerebral ischemia ${ }^{79}$ in a post-injury time-dependant manner. $^{80}$

\section{Clinical studies with hypothermia}

Clinical studies with moderate hypothermia of $32^{\circ} \mathrm{C}$ to $35^{\circ} \mathrm{C}$ for $1-14$ days have shown a beneficial effect on outcome in TBI patients with lowering of $\mathrm{ICP}^{81-84}$ and increase of cerebral perfusion pressure. ${ }^{83}$ However, two multicenter studies have failed to show beneficial effects of hypothermia. ${ }^{85,86}$ In infants and children, hypothermia treatment has shown preservation of oxidative defenses in the CSF after TBI. ${ }^{87} \mathrm{~A}$ meta-analysis of the clinical trials has shown that hypothermia reduced mortality and 
improved neurological outcome, although this was offset with an increased risk of pneumonia. ${ }^{88}$ No combination effects of magnesium and hypothermia have been reported in humans with TBI.

\section{Clinical studies with hyperoxia}

Management of hospitalized TBI patients should include adequate oxygen delivery to the brain with a decrease of lactate levels and $\mathrm{L} / \mathrm{P}$ ratio, representing a reversal of tissue hypoxia and an increase in cerebral metabolism. It is hypothesized that hyperoxia increases plasma oxygen content and thereby enhances tissue oxygen tension and mitochondrial function. ${ }^{89} \mathrm{~A}$ recent study in TBI patients has shown that hyperoxia restores mitochondrial function. ${ }^{90}$

Treatment of TBI patients with normobaric hyperoxia has shown variable results. Significant improvement ${ }^{91,92}$ or no improvement ${ }^{93}$ in cerebral metabolism, a decrease of lactate levels, ${ }^{91,94-96}$ a reduction of ischemic brain volume $^{92}$ and ICP ${ }^{96}$ were observed. Hyperoxia treatment has also resulted in either no change ${ }^{92}$ and in only some studies a decrease $\mathrm{e}^{90,96}$ of L/P ratio. No combination effects of magnesium and hyperoxia have been reported in humans with TBI.

\section{CONCLUSION}

The success of magnesium in attenuating the process of neurodegeneration in animal models of brain injury has been widely studied; however, preclinical studies have not yet been translated into successful clinical outcome. In TBI patients, administration of magnesium has shown varied results. Secondary brain insults and other parameters adversely affect the clinical outcome, and these could have unfavorably influenced the result of the efficacy studies with magnesium in TBI patients. In the design of clinical studies on brain injuries, secondary brain insults and parameters adversely affecting outcome need to be considered.

Pharmacokinetic and pharmacodynamic studies in normal rats have shown that after intraperitoneal administration magnesium can cross the $\mathrm{BBB}$ and enter the brain. In humans with brain insults, however, parenteral administration of magnesium resulted in low bioavailability in the CSF. This could have been a factor in the failure of magnesium to show consistent efficacy in clinical treatment of TBI. Increasing brain bioavailability of parenterally administered magnesium by disruption of the BBB is a necessary step in assessing the therapeutic benefits of magnesium after TBI.

In TBI patients, a serum concentration of magnesium at $1.25-2.5 \mathrm{mmol} / \mathrm{L}$ increased mortality. ${ }^{1}$ Dexanabinol was safe and efficacious in a Phase II clinical study; in a Phase III study, it was safe but not efficacious. A phase II study with progesterone reported no discernible harm with signs of benefit, and a phase III study is underway. Hyperoxia caused injury to the eye, lungs, heart, brain, and gastrointestinal tract and induced seizures ${ }^{97}$ and cerebral vasoconstriction. ${ }^{98}$ It is apparent that use of a single agent at a safe dose lacks efficacy and that adverse effects are observed at therapeutic doses or upon repeated administration. Multiple pathways are involved during the secondary phase of brain injury. Judicious combination of pharmacological agents and physiological interventions at safe and lowest effective doses are necessary for synergistic control of the pathways involved in the secondary phase of injury. Increasing brain bioavailability of magnesium using mannitol can allow for a low and safe dose of magnesium to be administered and promises to improve clinical outcome in TBI patients. Combination of magnesium and mannitol with pharmacological agents such as dexanabinol and progesterone and interventions with hyperoxia or hypothermia could be a safe and clinically successful neuroprotective regimen for the treatment of TBI.

\section{REFERENCES}

1. Temkin NR, Anderson GD, Winn HR, et al. Magnesium sulfate for neuroprotection after traumatic brain injury: a randomised controlled trial. Lancet Neurol 2007;6:29-38.

2. Dhandapani SS, Gupta A, Vivekanandhan S, Sharma BS, Mahapatra AK. Randomized controlled trial of magnesium sulphate in severe closed traumatic brain injury. Indian J Neurotrauma 2008; 5:27-33.

3. Hallak M, Berman RF, Irtenkauf SM, Evans MI, Cotton DB. Peripheral magnesium sulfate enters the brain and increases the threshold for hippocampal seizures in rats. Am J Obstet Gynecol 1992;167:1605-1610.

4. Hoane MR. Assessment of cognitive function following magnesium therapy in the traumatically injured brain. Magnes Res 2007; 20:229-236

5. Fuchs-Buder T, Tramèr MR, Tassonyi E. Cerebrospinal fluid passage of intravenous magnesium sulfate in neurosurgical patients J Neurosurg Anesthesiol 1997;9:324-328.

6. McKee JA, Brewer RP, Macy GE, et al. Analysis of the brain bioavailability of peripherally administered magnesium sulfate: a study in humans with acute brain injury undergoing prolonged induced hypermagnesemia. Crit Care Med 2005;33:661-666.

7. Thurnau GR, Kemp DB, Jarvis A. Cerebrospinal fluid levels of magnesium in patients with preeclampsia after treatment with intravenous magnesium sulfate: a preliminary report. Am J Obstet Gynecol 1987;157:1435-1438.

8. Stoica B, Byrnes K, Faden AI. Multifunctional drug treatment in neurotrauma. Neurotherapeutics 2009;6:14-27.

9. Vink R, Nimmo AJ. Multifunctional drugs for head injury. Neurotherapeutics 2009;6:28-42.

10. Maas AI, Murray G, Henney H 3rd, et al. Efficacy and safety of dexanabinol in severe traumatic brain injury: results of a phase III randomised, placebo-controlled, clinical trial. Lancet Neurol 2006; $5: 38-45$.

11. Bouma GJ, Muizelaar JP, Choi SC, Newlon PG, Young HF. Cerebral circulation and metabolism after severe traumatic brain injury: the elusive role of ischemia. J Neurosurg 1991;75:685-693.

12. Jenkins LW, Moszynski K, Lyeth BG, et al. Increased vulnerability of the mildly traumatized rat brain to cerebral ischemia: the use of controlled secondary ischemia as a research tool to identify common or different mechanisms contributing to mechanical and ischemic brain injury. Brain Res 1989;477:211-224.

13. Bergsneider M, Hovda DA, Shalmon E, et al. Cerebral hyperglycolysis following severe traumatic brain injury in humans: a 
positron emission tomography study. J Neurosurg 1997;86:241251.

14. Goodman JC, Valadka AB, Gopinath SP, Uzura M, Robertson CS. Extracellular lactate and glucose alterations in the brain after head injury measured by microdialysis. Crit Care Med 1999;27: 1965-1973.

15. Enblad P, Valtysson J, Andersson J, et al. Simultaneous intracerebral microdialysis and positron emission tomography in the detection of ischemia in patients with subarachnoid hemorrhage. J Cereb Blood Flow Metab 1996;16:637-644.

16. Persson L, Valtysson J, Enblad P, et al. Neurochemical monitoring using intracerebral microdialysis in patients with subarachnoid hemorrhage. J Neurosurg 1996;84:606-616.

17. Stocchetti N, Colombo A, Ortolano F, et al. Time course of intracranial hypertension after traumatic brain injury. J Neurotrauma 2007;24:1339-1346.

18. Balestreri M, Czosnyka M, Hutchinson $P$, et al. Impact of intracranial pressure and cerebral perfusion pressure on severe disability and mortality after head injury. Neurocrit Care 2006:4:8-13.

19. Obrenovitch TP, Urenjak J. Is high extracellular glutamate the key to excitotoxicity in traumatic brain injury? J Neurotrauma 1997; 14:677-698.

20. Fiskum G. Mitochondrial participation in ischemic and traumatic neural cell death. J Neurotrauma 2000;17:843-855.

21. Lifshitz J, Friberg H, Neumar RW, et al. Structural and functional damage sustained by mitochondria after traumatic brain injury in the rat: evidence for differentially sensitive populations in the cortex and hippocampus. J Cereb Blood Flow Metab 2003;23: 219-231.

22. van den Heuvel C, Vink R. The role of magnesium in traumatic brain injury. Clin Calcium 2004;14:9-14.

23. Garfinkel L, Garfinkel D. Magnesium regulation of the glycolytic pathway and the enzymes involved. Magnesium 1985;4:60-72.

24. Altura BM, Altura BT. Magnesium ions and contraction of vascular smooth muscles: relationship to some vascular diseases. Fed Proc 1981;40:2672-2679.

25. Hans CP, Chaudhary DP, Bansal DD. Magnesium deficiency increases oxidative stress in rats. Indian J Exp Biol 2002;40:12751279.

26. Garcia LA, Dejong SC, Martin SM, Smith RS, Buettner GR, Kerber RE. Magnesium reduces free radicals in an in vivo coronary occlusion-reperfusion model. J Am Coll Cardiol 1998;32: $536-539$.

27. Cernak I, Savic VJ, Kotur J, Prokic V, Veljovic M, Grbovic D. Characterization of plasma magnesium concentration and oxidative stress following graded traumatic brain injury in humans. J Neurotrauma 2000;17:53-68.

28. Chan MT, Boet R, Ng SC, Poon WS, Gin T. Magnesium sulfate for brain protection during temporary cerebral artery occlusion. Acta Neurochir Suppl 2005;95:107-111.

29. Napieralski JA, Raghupathi R, McIntosh TK. The tumor-suppressor gene, $p 53$, is induced in injured brain regions following experimental traumatic brain injury. Brain Res Mol Brain Res 1999;71: $78-86$.

30. Lee JS, Han YM, Yoo DS, et al. A molecular basis for the efficacy of magnesium treatment following traumatic brain injury in rats. J Neurotrauma 2004;21:549-561.

31. Nielsen S, Nagelhus EA, Amiry-Moghaddam M, Bourque C, Agre P, Ottersen OP. Specialized membrane domains for water transport in glial cells: high-resolution immunogold cytochemistry of aquaporin-4 in rat brain. J Neurosci 1997;17:171-180.

32. Ghabriel MN, Thomas A, Vink R. Magnesium restores altered aquaporin-4 immunoreactivity following traumatic brain injury to a pre-injury state. Acta Neurochir Suppl 2006;96:402-406.

33. Okiyama K, Smith DH, Gennarelli TA, Simon RP, Leach M, McIntosh TK. The sodium channel blocker and glutamate release inhibitor BW1003C87 and magnesium attenuate regional cerebral edema following experimental brain injury in the rat. J Neurochem 1995;64:802-809.

34. Heath DL, Vink R. Concentration of brain free magnesium following severe brain injury correlates with neurologic motor outcome. J Clin Neurosci 1999;6:505-509.
35. Bareyre FM, Saatman KE, Helfaer MA, et al. Alterations in ionized and total blood magnesium after experimental traumatic brain injury: relationship to neurobehavioral outcome and neuroprotective efficacy of magnesium chloride. J Neurochem 1999;73:271280.

36. Feldman Z, Gurevitch B, Artru AA, et al. Effect of magnesium given 1 hour after head trauma on brain edema and neurological outcome. J Neurosurg 1996;85:131-137.

37. Browne KD, Leoni MJ, Iwata A, Chen XH, Smith DH. Acute treatment with $\mathrm{MgSO}_{4}$ attenuates long-term hippocampal tissue loss after brain trauma in the rat. J Neurosci Res 2004;77: $878-883$

38. Hoane MR. Magnesium therapy and recovery of function in experimental models of brain injury and neurodegenerative disease. Clin Calcium 2004;14:65-70.

39. Hoane MR, Knotts AA, Akstulewicz SL, Aquilano M, Means LW. The behavioral effects of magnesium therapy on recovery of function following bilateral anterior medial cortex lesions in the rat. Brain Res Bull 2003;60:105-114.

40. Heath DL, Vink R. Optimization of magnesium therapy after severe diffuse axonal brain injury in rats. J Pharmacol Exp Ther 1999;288:1311-1316.

41. Bareyre FM, Saatman KE, Raghupathi R, McIntosh TK. Postinjury treatment with magnesium chloride attenuates cortical damage after traumatic brain injury in rats. J Neurotrauma 2000;17:10291039.

42. Heath DL, Vink R. Improved motor outcome in response to magnesium therapy received up to 24 hours after traumatic diffuse axonal brain injury in rats. J Neurosurg 1999;90:504-509.

43. Hoane MR, Barth TM. The window of opportunity for administration of magnesium therapy following focal brain injury is $24 \mathrm{~h}$ but is task dependent in the rat. Physiol Behav 2002;76:271-280.

44. Vink R, O'Connor CA, Nimmo AJ, Heath DL. Magnesium attenuates persistent functional deficits following diffuse traumatic brain injury in rats. Neurosci Lett 2003;336:41-44.

45. Heath DL, Vink R. Subdural hematoma following traumatic brain injury causes a secondary decline in brain free magnesium concentration. J Neurotrauma 2001;18:465-469.

46. Kahraman S, Ozgurtas T, Kayali H, Atabey C, Kutluay T, Timurkaynak E. Monitoring of serum ionized magnesium in neurosurgical intensive care unit: preliminary results. Clin Chim Acta 2003;334:211-215

47. Memon ZI, Altura BT, Benjamin JL, Cracco RQ, Altura BM Predictive value of serum ionized but not total magnesium levels in head injuries. Scand J Clin Lab Invest 1995;55:671-677.

48. Polderman KH, Bloemers FW, Peerdeman SM, Girbes AR. Hypomagnesemia and hypophosphatemia at admission in patients with severe head injury. Crit Care Med 2000;28:2022-2025.

49. Sakamoto T, Takasu A, Saitoh D, Kaneko N, Yanagawa Y, Okada Y. Ionized magnesium in the cerebrospinal fluid of patients with head injuries. J Trauma 2005;58:1103-1109.

50. Kafadar AM, Sanus GZ, Is M, et al. Prolonged elevation of magnesium in the cerebrospinal fluid of patients with severe head injury. Neurol Res 2007;29:824-829.

51. Canavero S, Bonicalzi V, Narcisi P. Safety of magnesium-lidocaine combination for severe head injury: the Turin Lidomag Pilot Study. Surg Neurol 2003;60:165-169.

52. Natale JE, Guerguerian AM, Joseph JG, et al. Pilot study to determine the hemodynamic safety and feasibility of magnesium sulfate infusion in children with severe traumatic brain injury. Pediatr Crit Care Med 2007;8:1-9.

53. Mosenthal AC, Livingston DH, Lavery RF, et al. The effect of age on functional outcome in mild traumatic brain injury: 6-month report of a prospective multicenter trial. J Trauma 2004;56:10421048.

54. Livingston DH, Lavery RF, Mosenthal AC, et al. Recovery at one year following isolated traumatic brain injury: a Western Trauma Association prospective multicenter trial. J Trauma 2005;59:1298 1304.

55. Chesnut RM, Marshall LF, Klauber MR, et al. The role of secondary brain injury in determining outcome from severe head injury. J Trauma 1993;34:216-222. 
56. Newfield P, Pitts L, Kaktis J, Hoff J. The influence of shock on mortality after head trauma. Crit Care Med 1980;8:254 (abstract).

57. Manley G, Knudson MM, Morabito D, Damron S, Erickson V, Pitts L. Hypotension, hypoxia, and head injury: frequency, duration, and consequences. Arch Surg 2001;136:1118-1123.

58. Rovlias A, Kotsou S. The influence of hyperglycemia on neurological outcome in patients with severe head injury. Neurosurgery 2000;46:335-342; discussion 342-343.

59. Laird AM, Miller PR, Kilgo PD, Meredith JW, Chang MC. Relationship of early hyperglycemia to mortality in trauma patients. J Trauma 2004;56:1058-1062.

60. Walia S, Sutcliffe AJ. The relationship between blood glucose, mean arterial pressure and outcome after severe head injury: an observational study. Injury 2002;33:339-344.

61. Bochicchio GV, Joshi M, Bochicchio KM, et al. Early hyperglycemic control is important in critically injured trauma patients. J Trauma 2007;63:1353-1358.

62. Zygun DA, Kortbeek JB, Fick GH, Laupland KB, Doig CJ. Nonneurologic organ dysfunction in severe traumatic brain injury. Crit Care Med 2005;33:654-660.

63. Jeremitsky E, Omert L, Dunham CM, Protetch J, Rodriguez A. Harbingers of poor outcome the day after severe brain injury: hypothermia, hypoxia, and hypoperfusion. J Trauma 2003;54:312319.

64. Schmid-Elsaesser R, Zausinger S, Hungerhuber E, Baethmann A, Reulen HJ. Neuroprotective effects of combination therapy with tirilazad and magnesium in rats subjected to reversible focal cerebral ischemia. Neurosurgery 1999;44:163-171.

65. Barbre AB, Hoane MR. Magnesium and riboflavin combination therapy following cortical contusion injury in the rat. Brain Res Bull 2006;69:639-646.

66. Eshhar N, Striem S, Kohen R, Tirosh O, Biegon A. Neuroprotective and antioxidant activities of HU-211, a novel NMDA receptor antagonist. Eur J Pharmacol 1995;283:19-29.

67. Feigenbaum JJ, Bergmann F, Richmond SA, et al. Nonpsychotropic cannabinoid acts as a functional $\mathrm{N}$-methyl-D-aspartate receptor blocker. Proc Natl Acad Sci U S A 1989;86:9584-9587.

68. Shohami E, Gallily R, Mechoulam R, Bass R, Ben-Hur T. Cytokine production in the brain following closed head injury: dexanabinol (HU-211) is a novel TNF- $\alpha$ inhibitor and an effective neuroprotectant. J Neuroimmunol 1997;72:169-177.

69. Knoller N, Levi L, Shoshan I, et al. Dexanabinol (HU-211) in the treatment of severe closed head injury: a randomized, placebocontrolled, phase II clinical trial. Crit Care Med 2002;30:548 -554.

70. Ogata T, Nakamura Y, Tsuji K, Shibata T, Kataoka K. Steroid hormones protect spinal cord neurons from glutamate toxicity. Neuroscience 1993;55:445-449.

71. Roof RL, Hoffman SW, Stein DG. Progesterone protects against lipid peroxidation following traumatic brain injury in rats. Mol Chem Neuropathol 1997;31:1-11.

72. O'Connor CA, Cernak I, Vink R. Both estrogen and progesterone attenuate edema formation following diffuse traumatic brain injury in rats. Brain Res 2005;1062:171-174.

73. Pettus EH, Wright DW, Stein DG, Hoffman SW. Progesterone treatment inhibits the inflammatory agents that accompany traumatic brain injury. Brain Res 2005;1049:112-119.

74. O'Connor CA, Cernak I, Johnson F, Vink R. Effects of progesterone on neurologic and morphologic outcome following diffuse traumatic brain injury in rats. Exp Neurol 2007;205:145-153.

75. Wright DW, Kellermann AL, Hertzberg VS, et al. ProTECT: a randomized clinical trial of progesterone for acute traumatic brain injury. Ann Emerg Med 2007;49:391-402.

76. Xiao G, Wei J, Yan W, Wang W, Lu Z. Improved outcomes from the administration of progesterone for patients with acute severe traumatic brain injury: a randomized controlled trial. Crit Care 2008;12:R61.

77. Zhu H, Meloni BP, Bojarski C, Knuckey MW, Knuckey NW. Post-ischemic modest hypothermia $\left(35^{\circ} \mathrm{C}\right)$ combined with intravenous magnesium is more effective at reducing CA1 neuronal death than either treatment used alone following global cerebral ischemia in rats. Exp Neurol 2005;193:361-368.
78. Campbell K, Meloni BP, Knuckey NW. Combined magnesium and mild hypothermia $\left(35^{\circ} \mathrm{C}\right)$ treatment reduces infarct volumes after permanent middle cerebral artery occlusion in the rat at 2 and 4 , but not 6 h. Brain Res 2008;1230:258-264.

79. Schmid-Elsaesser R, Hungerhuber E, Zausinger S, Baethmann A, Reulen HJ. Combination drug therapy and mild hypothermia: a promising treatment strategy for reversible, focal cerebral ischemia. Stroke 1999;30:1891-1899.

80. Zausinger S, Schöller K, Plesnila N, Schmid-Elsaesser R. Combination drug therapy and mild hypothermia after transient focal cerebral ischemia in rats. Stroke 2003;34:2246-2251.

81. Jiang J, Yu M, Zhu C. Effect of long-term mild hypothermia therapy in patients with severe traumatic brain injury: 1-year follow-up review of 87 cases. J Neurosurg 2000;93:546-549.

82. Qiu W, Zhang Y, Sheng H, et al. Effects of therapeutic mild hypothermia on patients with severe traumatic brain injury after craniotomy. J Crit Care 2007;22:229-235.

83. Smrcka M, Vidlák M, Máca K, Smrcka V, Gál R. The influence of mild hypothermia on ICP, CPP and outcome in patients with primary and secondary brain injury. Acta Neurochir Suppl 2005; 95:273-275.

84. Marion DW, Penrod LE, Kelsey SF, et al. Treatment of traumatic brain injury with moderate hypothermia. N Engl J Med 1997;336: $540-546$.

85. Clifton GL, Miller ER, Choi SC, et al. Lack of effect of induction of hypothermia after acute brain injury. N Engl J Med 2001;344: $556-563$

86. Shiozaki T, Hayakata T, Taneda M, et al.; Mild Hypothermia Study Group in Japan. A multicenter prospective randomized controlled trial of the efficacy of mild hypothermia for severely head injured patients with low intracranial pressure. J Neurosurg 2001; 94:50-54.

87. Bayir H, Adelson PD, Wisniewski SR, et al. Therapeutic hypothermia preserves antioxidant defenses after severe traumatic brain injury in infants and children [Erratum in: Crit Care Med 2009; 37:1536]. Crit Care Med 2009;37:689-695.

88. Peterson K, Carson S, Carney N. Hypothermia treatment for traumatic brain injury: a systematic review and meta-analysis. J Neurotrauma 2008;25:62-71.

89. Bullock MR. Hyperoxia: good or bad? J Neurosurg 2003;98:943944.

90. Tisdall MM, Tachtsidis I, Leung TS, Elwell CE, Smith M. Increase in cerebral aerobic metabolism by normobaric hyperoxia after traumatic brain injury. J Neurosurg 2008;109:424-432.

91. Rockswold SB, Rockswold GL, Vargo JM, et al. Effects of hyperbaric oxygenation therapy on cerebral metabolism and intracranial pressure in severely brain injured patients. J Neurosurg 2001;94: 403-411.

92. Nortje J, Coles JP, Timofeev I, et al. Effect of hyperoxia on regional oxygenation and metabolism after severe traumatic brain injury: preliminary findings. Crit Care Med 2008;36:273-281.

93. Diringer MN, Aiyagari V, Zazulia AR, Videen TO, Powers WJ. Effect of hyperoxia on cerebral metabolic rate for oxygen measured using positron emission tomography in patients with acute severe head injury. J Neurosurg 2007;106:526-529.

94. Menzel M, Doppenberg EM, Zauner A, Soukup J, Reinert MM, Bullock R. Increased inspired oxygen concentration as a factor in improved brain tissue oxygenation and tissue lactate levels after severe human head injury. J Neurosurg 1999;91:1-10.

95. Reinert M, Barth A, Rothen HU, Schaller B, Takala J, Seiler RW. Effects of cerebral perfusion pressure and increased fraction of inspired oxygen on brain tissue oxygen, lactate and glucose in patients with severe head injury. Acta Neurochir (Wien) 2003;145: 341-349; discussion 349-350.

96. Tolias CM, Reinert M, Seiler R, Gilman C, Scharf A, Bullock MR. Normobaric hyperoxia-induced improvement in cerebral metabolism and reduction in intracranial pressure in patients with severe head injury: a prospective historical cohort-matched study. J Neurosurg 2004;101:435-444.

97. Jenkinson SG. Oxygen toxicity. New Horiz 1993;1:504-511.

98. Bulte DP, Chiarelli PA, Wise RG, Jezzard P. Cerebral perfusion response to hyperoxia. J Cereb Blood Flow Metab 2007;27:69-75. 